\title{
Rotinas Familiares de Crianças com Necessidades Especiais em Família Adotiva
}

\author{
Fabíola Helena Oliveira Brandão Silva \\ Lilia Iêda Chaves Cavalcante \\ Universidade Federal do Pará
}

\begin{abstract}
RESUMO - Objetivou-se descrever as rotinas de três famílias, que adotaram crianças com necessidades especiais ,que tinham conhecimento prévio dessa condição infantil. Utilizou-se o método de Estudo de Casos Múltiplos. Os dados foram obtidos por meio de Entrevista Semiestruturada (ES), do Inventário de Rotina (IR) e do Diário de Campo (DC). Quanto às semelhanças entre os grupos familiares, identificou-se que são comuns as atividades de alimentação/higiene, descanso e lazer, envolvendo a participação dos pais, irmãs e babás, geralmente nos ambientes domésticos da família. Observou-se diferenças importantes nos padrões de atividades, companhias e ambientes onde as rotinas ocorriam. Conclui-se que as variações nas rotinas estão relacionadas às particularidades de cada criança, à estrutura e nível socioeconômico de cada família participante.
\end{abstract}

Palavras-chave: criança com necessidades especiais, rotinas familiares, adoção

\section{Family Routines for Children with Special Needs in Adoptive Families}

\begin{abstract}
This study aimed to describe the daily routines of three families who adopted children with special needs and had prior knowledge of this condition. We used the Multiple Case Study method. Data were obtained through Semi-structured Interview (SI), Inventory Routine (IR) and Field Diary (FD). Among the family groups the following common activities were identified: food/hygiene activities, rest and recreation, involving the participation of parents, sisters and nannies, usually in the home of the family. We observed significant differences in activity patterns, companionships and environments where the daily routines took place. We conclude that changes in routines are related to the particularities of each child, the structure and socioeconomic status of each participating family.
\end{abstract}

Keywords: child with special needs, family routines, adoption

As rotinas familiares consistem em regularidades comportamentais presentes no dia a dia das pessoas e grupos em diferentes contextos sociais. Caracterizam-se pela repetição e periodicidade de atividades que possibilitam o encontro dos membros familiares e a vivência de compromissos momentâneos.

Para Howe (2002), as rotinas são interações padronizadas, repetidas ao longo do tempo, a partir das quais se configuram os aspectos que as definem, tais como a previsibilidade e a estabilidade. Complementando essa argumentação, Deham (2003) afirma que as rotinas, mesmo apresentando regularidades, são modificadas pelas mudanças na estrutura familiar decorrentes das aquisições desenvolvimentais próprias de cada fase da vida, por exemplo, o nascimento de uma criança. Além disso, incluem também tempos regulares para fazer o dever de casa, tarefas em geral, alimentação e repouso, conforme argumenta Bomar (2004).

Também Fiese et al. (2002) estudaram as rotinas familiares, descobrindo que elas possibilitam acessar: a dinâmica familiar e seus vários processos; as formas pelas quais as perspectivas e as características individuais afetam o funcionamento familiar; o nível de influência desse agrupamento sobre o ajustamento de seus membros. Além disso, tais investigações tornam possível acessar os contextos ecológicos e culturais reguladores da vida familiar.

1 Endereço para correspondência: Rua Coronel Fontoura, sala 122, Bairro, Cidade Velha, Belém, PA, Brasil. CEP: 66015-260.

E-mail: brandaofabiola@gmail.com
Outras investigações com famílias empreendidas por Spagnola e Fiese (2007) apontaram evidências de que as rotinas familiares proveem a estrutura norteadora do comportamento e do clima emocional que subsidiam o desenvolvimento de cada um dos seus membros. As autoras verificaram também que as mudanças decorrentes das variações do ciclo de vida nas rotinas familiares promovem aquisições socioemocionais, linguísticas, acadêmicas e de habilidades sociais nas crianças inseridas nesses grupos, ressaltando, deste modo, o importante papel desempenhado por tais padrões e continuidades no processo de desenvolvimento humano.

Em complementariedade a esses achados, Fernandes, Boehs e Rumor (2011) verificaram em suas investigações que as rotinas familiares, como as conversas nos momentos das refeições ou a leitura de histórias infantis na hora de dormir, promovem ligações emocionais e trazem consequências favoráveis à saúde mental das crianças. Além disso, contribuem para o enriquecimento do vocabulário infantil, a construção de habilidades sociais e o desenvolvimento escolar, por oportunizarem o envolvimento das crianças nas atividades em díade ou em grupo. Tais rotinas requerem considerável energia e esforço dos pais, que podem vivenciar barreiras ou dificuldades para seu estabelecimento e cumprimento.

Em termos teóricos, Bronfenbrenner (1979/1996) discutiu a influência dos elementos pertencentes aos contextos ecológicos nos estudos tomados por ele para análise. $\mathrm{O}$ autor apontou o funcionamento da família como 
um contexto primário e abrangente em suas funções, que interfere no processo de desenvolvimento de seus membros, e é influenciado pelas características do contexto ecológico em que está inserido. Com base nessas reflexões, o autor afirmou que as atividades constituintes da rotina familiar são a manifestação mais imediata, tanto do desenvolvimento das pessoas, suas características e ações, quanto das forças ambientais (as características e ações de outras pessoas). As atividades encontradas nas diferentes rotinas familiares podem ser entendidas como comportamentos continuados que possuem momentos próprios (quantidades de movimentos) e para as quais são atribuídos significados pelos participantes nelas envolvidos. Outra dimensão dessas atividades refere-se à complexidade que podem apresentar, superando a perspectiva temporal e o objetivo imediato do contexto no qual estão sendo realizadas. Assim, durante a efetivação das mesmas, pode ocorrer a invocação de objetos, pessoas e eventos, ainda que esses não se façam presentes de modo aparente no ambiente imediato das atividades.

Mais recentemente, estudos de natureza empírica demonstram a vitalidade do tema das rotinas familiares e oferecem abordagens interessantes na contemporaneidade. Internacionalmente, os estudos verificaram o papel das rotinas familiares na vida das crianças (Churchill \& Stoneman, 2004), os significados atribuídos a elas por pais que fazem parte de populações com traços peculiares, como os semteto (Schultz-Krohn, 2004), e o emprego de estratégias que visam manutenção de rotinas em famílias de baixa renda (Sheely, 2010). A partir desses, observa-se em particular que Churchill e Stoneman (2004) reforçaram a hipótese de que a manutenção das rotinas possibilitava a diminuição de desordens de conduta infantil, o gerenciamento adequado das demandas emocionais das crianças e maior satisfação com a parentalidade. Já Schultz-Krohn (2004) concluiu que as rotinas familiares aumentam a intimidade entre as pessoas envolvidas, a manutenção ou o desenvolvimento do legado familiar, ou seja, a reprodução de valores que são importantes para esse grupo e conexões com a comunidade. Por sua vez, Sheely (2010) também verificou que as rotinas fortalecem o senso de união e o compartilhamento de valores entre os membros das famílias que enfrentam situações de vulnerabilidade pessoal e social.

Do ponto de vista das implicações das rotinas no desenvolvimento humano e no caso das pesquisas realizadas no contexto amazônico, Silva (2007) descreveu os parceiros, as rotinas e as interações de crianças para identificar as oportunidades de desenvolvimento geradas por esses aspectos. Os achados obtidos indicaram que as atividades e as companhias mantidas pelas crianças no dia a dia foram vistas como elementos componentes das rotinas familiares e por isso, descritores dos contextos de socialização infantil.

Em outro estudo, Silva, Pontes e Silva (2011) estudaram as interações estabelecidas por duas crianças e o ambiente físico e social em que se encontravam, a fim de investigar, nesses contextos, os efeitos provocados pelos padrões de atividades e relações na vida diária e no desenvolvimento infantil. Os resultados alcançados corroboraram as argumentações de Silva (2007) ao admitirem que o desenvolvimento humano, além de se estruturar por meio das características psicológicas individuais, liga-se amplamente aos contextos ecológicos nos quais os sujeitos estão inseridos, pois o ambiente tem a capacidade de diferenciar os comportamentos e as relações a serem desempenhados pelos integrantes de cada comunidade.

Em uma perspectiva quantitativa, Freire (2012) mapeou as atividades de rotinas de crianças ribeirinhas, seguindo os traços do contexto social e familiar desse grupo tradicional. A autora observou que os dias de semana tendiam a ser dedicados ao descanso (42\%), atividades escolares (19\%) e alimentação/higiene (11\%). Já nos sábados e domingos, foram também elevados os percentuais destinados ao descanso (45\%) e alimentação/higiene (11\%), sendo as tarefas escolares substituídas pelo lazer (35\%). Quanto às companhias, comumente as crianças permaneciam sozinhas a maior parte do tempo ou ficavam com os irmãos.

Visualizam-se, assim, os vários temas e métodos associados à investigação das rotinas familiares e as implicações que elas apresentam para o desenvolvimento humano em distintos contextos e populações infantis. Supõese, desse modo, que esses processos ocorram tanto nos grupos familiares consanguíneos, quanto naqueles em que há a integração de pessoas por meio da adoção.

Outro enfoque de estudos contempla as modificações das rotinas familiares, ocasionadas por pressões ambientais. Bomar (2004) verificou que elas podem ocorrer, tanto pela interação dos seus membros com outros subsistemas, quanto pelas mudanças presentes no cotidiano das pessoas envolvidas nesse grupo, como o surgimento de doenças infantis crônicas, início da escolarização, adoção, óbitos, dentre outros acontecimentos.

No caso de famílias em que as crianças apresentam doenças crônicas ou necessidades especiais, essas dificuldades nas modificações das rotinas tendem a ser maximizadas, conforme alguns estudos na atualidade. Althoff, Renck e Sakae (2005), por exemplo, investigaram o impacto dos problemas de saúde das crianças que necessitam de cuidados especiais (diabéticas e queimadas) sobre as suas famílias. Quanto às rotinas familiares, por um lado, o estudo mostrou o incremento da união entre os membros da família e, de outro, um esforço deles para reestruturá-las, com o objetivo de possibilitar as devidas adequações às novas demandas trazidas pela criança. Dentre essas, foram ressaltadas as preocupações relativas às atividades relacionadas ao uso dos espaços, do tempo, dos recursos e da rede de apoio à família.

Verifica-se, assim, conforme Althoff et al. (2005), que a integração no convívio familiar de uma criança que requer cuidados especiais, compreende a estruturação de espaços específicos, por exemplo, locais mais amplos que possibilitem o deslocamento de uma pessoa com dificuldades motoras; a redução da jornada de trabalho pelos cuidadores, com o objetivo de direcionar mais tempo para o atendimento das necessidades da criança e o replanejamento do orçamento familiar, de forma a garantir o acesso a recursos que garantam a manutenção do bem-estar e da saúde.

Já para Spagnola e Fiese (2007), nas famílias em que estão presentes crianças com necessidades especiais, as mudanças nas rotinas ocorrem por meio de ajustes e adequações que proverão os recursos adicionais demandados por essas crianças, como por exemplo, a necessidade de uma maior quantidade de tempo a ser utilizado em atendimentos médicos, clínicos e terapêuticos relevantes à promoção 
de aquisições desenvolvimentais. Contudo, as autoras ponderam que, para algumas famílias, essas alterações nas rotinas podem ser mais suaves, acontecendo na medida em que são progressivamente assimiladas as informações sobre a condição de saúde física e mental de seus filhos e o esperado em termos desenvolvimentais. Para outras, estabelecer e manter rotinas diárias pode ser contestado por demandas conflitantes, tais como, tempo familiar escasso para a efetivação das rotinas, características individuais dos membros do grupo e os desafios presentes no exercício de parentalidade de uma criança com necessidades especiais. Nesse sentido, Sheely (2010) obteve um interessante achado: a existência de correlação negativa entre o nível salarial e a manutenção de rotinas, sugerindo que mães com rendas elevadas contratam bens e serviços auxiliares à manutenção das atividades diárias que envolvem os cuidados com os seus filhos, sem que necessariamente elas estejam presentes. Compreende-se assim, que os resultados desses estudos demonstram que as rotinas espelham as alterações sofridas na estrutura e dinâmica das famílias ao longo dos anos, mas também contribuem para introduzir e sedimentar uma reconfiguração das funções e papéis nesses grupos. Em outras palavras, as rotinas sofrem a ação do contexto familiar e social onde estão inseridas, mas elas também são indutoras de mudanças e permanências nesses ambientes.

Nesses termos, supõe-se que a estruturação de novas rotinas familiares pode ser ainda mais desafiante quando a chegada de crianças não ocorre por meio biológico, mas por adoção. Em parte porque esse tipo de relação requer o desafio de estabelecer vínculo com crianças e adolescentes que não puderam permanecer sob a responsabilidade de sua família biológica ou extensa, conforme disposto no Estatuto da Criança e do Adolescente - ECA (Brasil, 1990), e suas alterações mais recentes (Brasil, 2009).

As particularidades presentes na adoção exercem influência na estruturação das rotinas familiares e são observadas em várias direções, compreendendo o fato de que a preparação para o exercício do papel parental envolve tão somente o aspecto emocional, o contrário do que é verificado na concepção biológica, na qual o pré-natal da mãe gestante é também físico. Outra peculiaridade da adoção é a história de vida pregressa do filho, fator inexistente na gestação (Schettini, Amazonas, \& Dias, 2006). Quando a criança adotada apresenta necessidades especiais, além dessas diferenças já comentadas, existem ainda outras demandas infantis específicas, suscitando profundas modificações tanto na estrutura, quanto na dinâmica da família adotiva.

Por se considerar a importância da investigação do tema nesse contexto específico, objetivou-se descrever as rotinas familiares de crianças adotadas que possuem necessidades especiais decorrentes de problemas de saúde que dificultaram e limitaram seus processos desenvolvimentais. Para tanto, o presente estudo teve o propósito de identificar as atividades (o que fazem), as companhias (com quem fazem) e os ambientes (onde fazem) e sua representação temporal (quando fazem) nas rotinas familiares, procurando compreendê-los como elementos do contexto ecológico em que essas crianças passaram a viver após a adoção.

\section{Método}

Realizou-se um estudo cuja abordagem foi quantiqualitativa e de natureza descritiva, utilizando-se o método de Estudo de Casos Múltiplos (Yin, 2003/2010). Elaborou-se um protocolo de pesquisa no qual estavam previstos: a) Os dados a serem coletados, em termos de fontes, qualidade e procedimentos necessários; b) As análises a serem realizadas, mais especificamente a integração dos dados quantitativos e qualitativos, a descrição de cada caso estudado e a verificação de similaridades e diferenças entre eles.

\section{Participantes}

Participaram do estudo três famílias que adotaram crianças com necessidades especiais. A seleção foi norteada por três critérios: a) Processos que haviam tramitado parcial ou integralmente na $1^{\text {a }}$ Vara de Infância e Juventude de Belém, vinculada ao Tribunal de Justiça do Estado do Pará (TJPA), após a criação do Cadastro Nacional de Adoção (CNA), em abril de 2008; b) Casos nos quais os pais adotivos possuíam conhecimento prévio das particularidades das crianças, antes de pleitearam a adoção; c) Disponibilidade das pessoas envolvidas, nos casos selecionados, para participar da pesquisa e contribuir com as informações solicitadas.

\section{Instrumentos e Materiais}

1. Roteiro de Entrevista Semiestruturada (RES): cujas questões versavam sobre o cotidiano das famílias e seus filhos por adoção, desde o momento dos preparativos para o acolhimento dessas crianças até a consolidação do vínculo de filiação com elas.

2. Inventário de Rotina (IR): o instrumento foi reelaborado por Silva (2006) durante seus estudos com famílias ribeirinhas. Após essas modificações, o IR passou a ser uma ficha para o registro padronizado das informações prestadas pelo responsável que tem conhecimento sobre os cuidados diários destinados às crianças. $\mathrm{O}$ instrumento permite: a) classificar as atividades realizadas dentro de subcategorias, como dormir, higiene pessoal, escola e assistir televisão, dentre outras; b) mensurar o tempo gasto em cada atividade mencionada, considerando-se intervalos de 15, 30, 45 e 60 minutos; c) registrar o local de realização das atividades; e d) identificar a companhia envolvida em cada atividade, tais como irmãos, parentes ou amigos. O IR considera também dois aspectos: os fatos ocorridos no dia imediatamente anterior à aplicação do instrumento e as atividades realizadas no último domingo. Essa diferenciação temporal é resultante da necessidade de se ter acesso às atividades rotineiras de um dia típico da semana e àquelas referentes ao fim de semana.

3. Registros do Diário de Campo (DC): foi utilizado para registros de informações adicionais, acessadas a partir da observação da rotina e da dinâmica familiar, com a finalidade de apoiar a análise dos dados ou clarificar os achados dos outros instrumentos e materiais utilizados. 


\section{Procedimentos}

Com a obtenção da aprovação do Comitê de Ética de Medicina Tropical da Universidade Federal do Pará e da autorização do juiz da $1^{\text {a }}$ Vara da Infância e Juventude de Belém, realizou-se o levantamento dos processos de adoção de crianças com necessidades especiais que se enquadravam nos critérios de inclusão estabelecidos. Os prováveis participantes foram contatados por meio de contato telefônico.

Após o aceite deles, definiu-se o horário e o local indicado pelos participantes para a realização das coletas. Durante esses encontros, realizou-se a entrevista com as mães das crianças e a aplicação do IR. Os dados provenientes das transcrições das entrevistas e dos registros feitos no DC foram analisados qualitativamente. Já aqueles resultantes da aplicação do IR foram tratados por meio de estatística descritiva. Os procedimentos realizados permitiram a descrição das principais atividades desenvolvidas pelos subsistemas familiares, os locais de realização dessas, as pessoas envolvidas e o tempo dispendido em cada uma delas.

\section{Resultados}

\section{Caracterização dos grupos familiares}

\section{Grupo Familiar Um (GF1)}

a) Criança adotada: sexo feminino, 3 anos, surdo-cega e prematura. No momento da coleta de dados, havia consolidado a marcha há pouco tempo, graças a tratamento fisioterapêutico a que vinha sendo submetida, na família adotiva, desde os primeiros meses de vida. Contudo, não apresentava articulações verbais, vocalizando sons incompreensíveis. Estava engajada em acompanhamento fonoaudiólogo para desenvolver a fala. Também recebia atendimento psicológico. No âmbito escolar, era acompanhada, com exclusividade, por uma psicopedagoga nas atividades de sala de aula, profissional responsável por elaborar os materiais e recursos pedagógicos utilizados na sua aprendizagem, os quais consideravam as suas particularidades. Em casa, os cuidados com a sua higiene corporal, alimentação e companhia nos deslocamentos para a escola e outros ambientes que frequentava eram de responsabilidade de uma cuidadora profissional (babá) todos os dias da semana.

b) Mãe adotiva: 36 anos, solteira, bacharel em direito, empresária e com renda de cerca de 20 salários mínimos. $\mathrm{Na}$ maior parte do dia, estava intensamente envolvida em suas atividades de trabalho, compartilhando momentos da vida diária com as duas filhas, no período noturno, durante a semana e aos domingos.

c) Filha biológica: sexo feminino, 6 anos de idade. Tinha sua cuidadora profissional exclusiva (babá), estudava na mesma escola e no mesmo horário que a irmã. Compartilhava com esta o quarto e os brinquedos, além de vivenciar com ela alguns momentos de lazer.

\section{Grupo Familiar Dois (GF2).}

a) Criança adotada: sexo masculino, 4 anos, portadora de hidrocefalia com macrocefalia extrema, diagnosticada desde o período de vida intrauterina. No momento da coleta de dados, a criança não apresentava a marcha desenvolvida e sua fala restringia-se a repetição de alguns vocábulos. Reagia a estímulos coloridos e tinha conhecimento de manuseio de aparelho eletrônico (celular). Permanecia deitada, no quarto compartilhado com sua mãe, durante todo o dia.

b) Mãe adotiva: 47 anos, solteira, ensino médio completo, não trabalhava, apresentava renda em torno de sete salários mínimos (advinda de uma pensão deixada pelo seu pai à sua genitora), sem filhos biológicos. Era a principal responsável pelos cuidados com seu filho, mas, esporadicamente contratava uma cuidadora profissional para ajudá-la no atendimento das necessidades da criança adotada, sobretudo no período noturno.

\section{Grupo Familiar Três (GF3).}

a) Criança adotada: sexo masculino, 5 anos, com hipótese diagnóstica de atraso global leve de desenvolvimento, de origem indeterminada. Apresentava a marcha consolidada e articulação verbal relativamente abaixo do esperado para sua idade cronológica, pois conseguia elaborar e desenvolver estórias, descrever sobre fatos cotidianos, ainda que demorasse na pronúncia de alguns vocábulos. Seus déficits estavam centrados em aspectos do desenvolvimento cognitivo, coordenação motora fina e habilidades sociais.

b) Pais adotivos: pai, 52 anos, casado, administrador, empregado de organização privada e mãe, 46 anos, casada, terapeuta ocupacional, servidora pública de programa de acolhimento institucional, ambos de religião católica e com renda familiar em torno de 15 salários mínimos. O pai trabalhava em horário integral, porém flexível. Já a mãe havia finalizado vínculo empregatício no período vespertino, para dedicar-se aos cuidados com o menino.

c) Filhas biológicas: tinham 22 e 18 anos, universitárias. As jovens contribuíam ativamente para o atendimento das necessidades do menino, buscando-o na escola, fornecendo alimentação, auxiliando nos hábitos de higiene e dever de casa. Também se responsabilizavam por fazê-lo dormir, compartilhando o espaço de descanso e fazendo companhia para a criança durante o período noturno.

\section{Comparando as rotinas familiares}

Para efetuar a comparação das rotinas das crianças participantes do estudo, primeiramente foram analisados os dados obtidos por meio da aplicação do IR, que possibilitou acessar as atividades, os tempos, as pessoas envolvidas, as relações estabelecidas e os ambientes em que elas ocorrem, tanto durante um dia típico, quanto no final de semana. Em seguida, estes foram complementados pelas informações advindas das entrevistas e dos registros do diário de campo.

$\mathrm{Na}$ apresentação dos achados, destaca-se a utilização do termo Inexistente para indicar a impossibilidade de realização da atividade pela criança (por exemplo, no GF1, a criança 
surdo-cega assistir televisão). Já o termo Não mencionado refere-se às atividades que estavam presentes nas rotinas, todavia, não foram verbalizadas pelos participantes durante a aplicação do IR. Um exemplo foi o engajamento em terapias da criança com atraso global leve de desenvolvimento, que foi mencionada somente durante a entrevista do GF3.

$\mathrm{Na}$ relação entre as atividades e o tempo utilizado na sua realização, os períodos mais extensos foram direcionados para descanso e lazer nos três grupos familiares. Já as adotada, não se envolvendo em outras atividades externas ao ambiente doméstico. Dentre as particularidades observadas, no GF1 constatou-se a presença da babá tanto na semana, quanto nos sábados e domingos. No GF2, a mãe é a principal cuidadora, não tendo auxílio contínuo de outras pessoas. E no GF3, observou-se a participação dos avós nas rotinas familiares.

Tabela 1. Tipos de atividades e os percentuais de tempo por grupo familiar

\begin{tabular}{lcccccc}
\hline \multirow{2}{*}{$\begin{array}{c}\text { Atividades e Tempos } \\
\text { Utilizados }\end{array}$} & \multicolumn{2}{c}{ GF1 } & \multicolumn{2}{c}{ GF2 } & \multicolumn{2}{c}{ GF3 } \\
\cline { 2 - 7 } & Semana & Fim de Semana & Semana & Fim de Semana & Semana & Fim de Semana \\
\hline Alimentação e Higiene & $16,31 \%$ & $12,14 \%$ & $10,41 \%$ & $10,41 \%$ & $15,62 \%$ & $18,74 \%$ \\
Descanso & $36,45 \%$ & $47,91 \%$ & $47,91 \%$ & $47,91 \%$ & $41,66 \%$ & $41,66 \%$ \\
Deslocamentos & $7,63 \%$ & Não mencionado & Inexistente & Inexistente & $3,12 \%$ & Não mencionado \\
Escola & $16,66 \%$ & Inexistente & Inexistente & Inexistente & $22,91 \%$ & Inexistente \\
Lazer & $8,33 \%$ & $29,16 \%$ & $18,75 \%$ & $18,75 \%$ & $25 \%$ & $31,25 \%$ \\
Terapias & $6,25 \%$ & Inexistente & Inexistente & Inexistente & Não mencionado & Inexistente \\
Atividades relaxantes & $10,41 \%$ & Não mencionado & Inexistente & Inexistente & Inexistente & Inexistente \\
Assistir televisão & Inexistente & Inexistente & $25 \%$ & $25 \%$ & Não mencionado Não mencionado \\
Prática religiosa & Inexistente & Inexistente & Inexistente & Inexistente & Inexistente & $6,25 \%$ \\
\hline
\end{tabular}

Nota: Os percentuais de tempo obtidos referem-se às parcelas de horas utilizadas na realização das atividades no período de um dia.

particularidades verificadas foram: no GF1, a atividade denominada de momento relaxante, pela mãe, que consiste na interação táctil dela com sua filha adotiva, no período noturno. No GF2, o elevado percentual de tempo dedicado a assistir televisão, por motivo da imobilidade física da criança adotada. E no GF3, a participação do adotado em atividade de prática religiosa, em conjunto com seus familiares, no final de semana.

A Tabela 1 demonstra as atividades que foram mapeadas e os respectivos percentuais de tempo gastos em cada uma delas.

Chama a atenção, ainda, a presença destacada das mães e o tempo dedicado às atividades diárias de cuidado à criança nos três grupos estudados. Contudo, os períodos de envolvimento materno nas atividades variaram consideravelmente, pois no GF1 a mãe apresenta carga horária de trabalho extensa, enquanto no GF2, a mãe é a principal cuidadora da criança
A seguir, a Tabela 2 ilustra as companhias em cada uma das atividades e os percentuais de tempo utilizados em cada uma delas, nos três grupos familiares estudados.

No que se refere aos tipos de atividades que compõem as rotinas familiares e os ambientes onde elas acontecem, identificou-se que nos domicílios de cada um dos três grupos familiares, acontecem: alimentação, higiene, descanso, atividade relaxante e assistir televisão. A particularidade dessa relação atividade versus ambiente é vivenciada pelo GF2, no qual a criança não frequenta o ambiente escolar, ao contrário dos adotados do GF1 e GF3.

A Tabela 3 expõe os ambientes onde acontecem as atividades, em cada um dos grupos estudados.

As entrevistas possibilitaram o detalhamento dos achados obtidos por meio do IR. No GF1, a mãe adotiva expressou suas preocupações quanto às repercussões de sua extensa jornada de trabalho, pois a criança adotada permanece a

Tabela 2. Companhias nas atividades e os percentuais de tempo por grupo familiar

\begin{tabular}{lcccccc}
\hline \multirow{2}{*}{$\begin{array}{c}\text { Companhias e } \\
\text { Tempos }\end{array}$} & \multicolumn{2}{c}{ GF1 } & \multicolumn{2}{c}{ GF2 } & \multicolumn{2}{c}{ GF3 } \\
\cline { 2 - 7 } & Semana & Fim de Semana & Semana & Fim de Semana & Semana & Fim de Semana \\
\hline Mãe & $10,41 \%$ & $27,08 \%$ & $100 \%$ & $100 \%$ & $20,83 \%$ & $49,99 \%$ \\
Pai & Inexistente & Inexistente & Inexistente & Inexistente & $3,12 \%$ & $49,99 \%$ \\
Babá & $38,52 \%$ & $14,22 \%$ & Inexistente & Inexistente & Inexistente & Inexistente \\
Irmã (s) & $36,45 \%$ & $47,91 \%$ & Inexistente & Inexistente & $47,90 \%$ & $100 \%$ \\
Avós & Inexistente & Inexistente & Inexistente & Inexistente & $28,15 \%$ & Inexistente \\
\hline
\end{tabular}

Nota: Os percentuais de tempo obtidos referem-se às parcelas de horas que as crianças adotadas permanecem na companhia de seus cuidadores, considerando-se o período de um dia. 
Tabela 3. Tipos de atividades e os ambientes de realização de cada uma delas por grupo familiar

\begin{tabular}{|c|c|c|c|c|c|c|}
\hline \multirow{2}{*}{$\begin{array}{c}\text { Atividades e os } \\
\text { Ambientes que } \\
\text { ocorrem }\end{array}$} & \multicolumn{2}{|c|}{ GF1 } & \multicolumn{2}{|c|}{ GF2 } & \multicolumn{2}{|c|}{ GF3 } \\
\hline & Semana & Fim de Semana & Semana & Fim de Semana & Semana & Fim de Semana \\
\hline Alimentação e Higiene & Domicílio & Domicílio & Domicílio & Domicílio & Domicílio & Domicílio \\
\hline Descanso & Domicílio & Domicílio & Domicílio & Domicílio & Domicílio & Domicílio \\
\hline Deslocamentos & $\begin{array}{l}\text { Ambientes } \\
\text { variados }\end{array}$ & Não mencionado & Inexistente & Inexistente & $\begin{array}{l}\text { Ambientes } \\
\text { variados }\end{array}$ & Não mencionado \\
\hline Escola & $\begin{array}{l}\text { Instituição } \\
\text { escolar }\end{array}$ & Inexistente & Inexistente & Inexistente & $\begin{array}{l}\text { Instituição } \\
\text { escolar }\end{array}$ & Inexistente \\
\hline Lazer & $\begin{array}{l}\text { Ambientes } \\
\text { variados }\end{array}$ & $\begin{array}{l}\text { Ambientes } \\
\text { variados }\end{array}$ & Domicílio & Domicílio & $\begin{array}{l}\text { Ambientes } \\
\text { variados }\end{array}$ & $\begin{array}{l}\text { Ambientes } \\
\text { variados }\end{array}$ \\
\hline Terapias & Consultórios & Inexistente & Inexistente & Inexistente & Consultórios & Inexistente \\
\hline Atividades relaxantes & Domicílio & Não mencionado & Inexistente & Inexistente & Inexistente & Inexistente \\
\hline Assistir televisão & Inexistente & Inexistente & Domicílio & Domicílio & Não mencionado & Não mencionado \\
\hline Prática religiosa & Inexistente & Inexistente & Inexistente & Inexistente & Inexistente & Igreja \\
\hline
\end{tabular}

Nota: O termo Ambientes Variados foi utilizado para demonstrar que as atividades investigadas ocorrem em outros locais além desses que foram detalhados na tabela

maior parte do dia com a babá, sendo reduzido o tempo sob os seus cuidados e companhia. Esse é um aspecto da rotina familiar que começa a incomodar a mãe porque, na sua percepção, pode estar dificultando a construção do vínculo afetivo que liga a filha adotiva a ela, conforme sugere o trecho da entrevista transcrito a seguir.

Ela (diz referindo-se à filha adotiva) passa quase 24 horas por dia com a babá. Eu tô trabalhando e eu tenho momentos com ela, com as duas (diz referindo-se às filhas biológica e adotiva). Então, por exemplo, com a maior facilidade ela me troca pela babá, mas não posso me noiar com isso, né? Isso é uma coisa que ao longo do tempo tem que ser construida. Com a minha filha mais velha, isso não acontece, porque ela já tem seis anos. Ela (referindo-se à filha biológica) troca a babá facilmente por mim, entendeu? Mas isso é uma coisa que tem que ser construída, agora a gente só não pode ficar neurótica, se culpando e tal, por que tem que dar conta de várias atividades.

Em outro extremo, a mãe adotiva do GF2 é a principal cuidadora do filho adotivo, não desenvolvendo atividades laborais, nem acadêmicas. Sobre essa característica da rotina da família, a mãe, quando entrevistada, apresentou seu ponto de vista quanto ao cotidiano vivido ao lado do filho adotivo:

Os dias são sempre iguais. Sou sempre, eu e ele. Minha mãe já tá com certa idade, ela não pode ajudar nos cuidados, mas ajuda no financeiro. No resto, sou eu que faço tudo por ele. Às vezes, quando eu tenho que sair, é que chamo uma pessoa que mora aqui perto de casa para ficar com ele. Mas é rápido, saio, resolvo um problema e volto logo. Só quando vou para casa da (menciona o nome de uma amiga) é que fico mais tranquila, porque lá tem várias pessoas para ajudar ou quando vou à igreja. Mas, no geral, sou sempre eu e ele.

No GF3 verifica-se participação de um maior número de pessoas e compartilhamento dos cuidados com a criança adotada. Sobre esse cotidiano, a mãe adotiva fez a descrição de um dia de semana, durante a entrevista realizada:

\begin{abstract}
Bem, eu sou a primeira a levantar. Eu me acordo às cinco horas, ai vou, faço meu café, tomo meu café tranquila. Ai, dou o mingau dele (diz referindo-se ao filho adotivo). Acordo meu marido e vou tomar banho. Depois que ele toma o mingau, toma banho junto com o pai. Aí eu já estou pronta e a gente sai pra aula, meu marido me deixa no trabalho e vai deixá-lo no colégio. Na volta dele ou o meu marido vai buscá-lo ou a minha filha... Nas sextas, à tarde, ele (diz referindo-se ao filho adotivo) faz capoeira e psicologia e os outros dias a gente deixa assim, para a gente estar acompanhando, fazendo dever juntos. E eu não estou mais trabalhando à tarde, só pela manhã e ai é o tempo que eu tenho pra ele. Já à noite é assim, às sete horas, ele é muito reloginho; ele diz: "mãe minha barriga tá com fominha".. Dai eu digo: "vamos jantar filho". Ele vai, se as meninas (diz referindo-se às filhas biológicas) estiverem aqui, fica todo mundo junto, elas ajudam também e ai depois ele vai, escova os dentes, coloca o pijama e eu digo: "meu filho está na hora de dormir"... Isso umas nove horas da noite.
\end{abstract}

\section{Discussão}

Verificou-se, nos grupos familiares investigados, que as atividades para as quais foi destinada maior quantidade de tempo durante a semana foram: descanso, escola, alimentação/higiene, assistir televisão e lazer. Esses achados podem ser explicados pelo fato de que as crianças inseridas nesses grupos familiares estão na primeira infância, momento de vida caracterizado por extensos períodos de descanso, necessário à ação de hormônios e outros substâncias que atuam na maturação dos sistemas biológicos, conforme argumentaram Bomar (2004) e Deham (2003) ao relacionarem as rotinas familiares à saúde e desenvolvimento infantil. Nesse período da vida, o envolvimento em lazer também é 
bastante expressivo, por ser uma atividade potencializadora tanto da socialização da criança na primeira infância, quanto da aprendizagem relevante à vida adulta.

A frequência à escola é outra atividade que demanda expressiva quantidade de tempo, porque é nessa instituição que as ações das outras pessoas consistem em intervenções planejadas e estáveis, repetidas ao longo do tempo e direcionadas à aquisição de habilidades e conhecimentos (Howe, 2002). Para crianças com necessidades especiais, a escola desempenha um papel de fundamental importância no desenvolvimento, contribuindo, sobremaneira para a socialização em outros grupos além da família, e no acesso a conhecimentos valorizados culturalmente e necessários à vida em sociedades urbanas complexas, conforme já argumentou Silva (2007).

As atividades referentes à alimentação/higiene também auxiliam a maturação biológica do organismo. A primeira possibilita o acesso a elementos nutricionais demandados no processo de maturação, enquanto a higiene promove a saúde de um modo geral (Bomar, 2004; Deham, 2003).

Nos finais de semana, foi observada a manutenção de elevados períodos de tempo dedicados ao descanso, alimentação/higiene e assistir televisão (esta atividade mais especificamente no GF2). Já o período dedicado à escola foi substituído por mais horas de lazer que, nos grupos familiares investigados, compreendeu o compartilhamento de atividades de recreação, nas quais estavam envolvidos tanto os membros dos grupos familiares quanto a cuidadora profissional. Nesses momentos, ocorreram valiosas interações que possibilitam a consolidação dos vínculos de parentalidade, filiação e de afetividade entre os irmãos, conforme a literatura sobre rotinas familiares vem apontando. Schultz-Krohn (2004), por exemplo, já observou que as rotinas promovem o aumento da intimidade e a manutenção de um legado familiar, à semelhança do que foi pontuado por Sheely (2010), que percebeu um fortalecimento do senso de união e compartilhamento de valores quando os membros familiares sistematicamente envolvem-se em atividades conjuntas.

Os tipos de atividades encontradas nos três grupos familiares estudados e as suas respectivas distribuições de tempo no cotidiano familiar foram corroborados, em parte, pelos achados de Freire (2012) em suas investigações de rotinas familiares de crianças ribeirinhas, as quais dedicavam elevado número de horas do dia de semana ao descanso, escola e alimentação/higiene. E nos finais de semana, os percentuais mais expressivos referiam-se ao descanso, ao lazer e à alimentação/higiene. As diferenças de resultados entre as pesquisas podem ser explicadas pelo fato de que as crianças participantes do presente estudo apresentam necessidades especiais e são mais jovens do que as investigadas por Freire (2012), o que provoca diferenciações no tipo de atividade realizada comumente e na quantidade de tempo dedicado a elas.

No que se refere ao tempo gasto com tratamentos especializados para o atendimento das necessidades especiais dessas crianças, verificou-se que, no GF1, ele está restrito aos dias de semana, representando $6,25 \%$ do dia. No GF2, essa atividade não faz parte da rotina, restringindo-se a consultas médicas eventuais. No GF3, esse tempo não foi estimado quantitativamente durante a aplicação do IR, apesar de ter sido citado, como uma atividade periódica semanal, na entrevista com a mãe adotiva. Essas constatações podem ser explicadas pelos achados de pesquisas anteriores (Althoff et al., 2005; Spagnola \& Fiese, 2007) sobre as modificações de rotinas nas famílias de crianças com necessidades especiais. Conforme foi observado nessas investigações, as alterações nas rotinas familiares podem ser mais suaves, constituindo-se progressivamente como fontes de apoio e confiança, na medida em que são paulatinamente assimiladas as informações adequadas sobre as condições de seus filhos.

A partir das análises processadas, depreendeu-se, ainda, que a qualidade das relações estabelecidas entre as crianças adotadas e o ambiente social em que estão inseridas, variou de acordo com as estruturas de cada um dos grupos familiares substitutos. Nos grupos monoparentais, verificou-se dois extremos: no GF1, a relação mãe-criança está restrita a poucas horas de convívio, sendo as interações da criança realizadas predominantemente com a babá, inclusive nos finais de semana. O extremo oposto é observado em GF2, no qual há uma relação exclusiva de cuidados estabelecida entre a mãe e a criança, já que ela não conta com auxílio de seus familiares, nem de uma cuidadora profissional. No GF3, há uma maior variedade de relações no ambiente social da criança, que convive diariamente com seus pais adotivos, irmãs, tia e avós maternos, os quais compartilham os cuidados direcionados a ele. Esses achados estão de acordo com o que observou Sheely (2010), que identificou a existência de correlação negativa entre o nível salarial e a manutenção de rotinas, sugerindo que mães com rendas elevadas contratam bens e serviços auxiliares à manutenção das atividades diárias que envolvem os cuidados com os seus filhos, sem que necessariamente elas estejam presentes, conforme foi visualizado no GF1.

A qualidade das relações estabelecidas com as crianças adotadas também variou conforme a composição da rede social de apoio dessas famílias. O GF2 é o que apresenta maior dificuldade nesse sentido, já que não há participação dos parentes (avós e tios) nas rotinas familiares vivenciadas, pois desde o início eles não apoiaram a adoção da criança. Esporadicamente, essa família recebe auxílio de amigos da mãe adotiva, o qual eventualmente estabelece interações com essas pessoas. Por outro lado, os outros grupos familiares (GF1 e GF3) recebem diariamente auxílio, tanto da família extensa quanto da rede de apoio social mais ampla, constituída por profissionais que executam tratamentos especializados com as crianças adotadas. A importância desses contextos ecológicos para a manutenção das rotinas familiares e consolidação do desenvolvimento humano já foi apontada por Fiese et al. (2002) e Silva, Pontes e Silva (2011).

A qualidade dessas relações interpessoais também foi destacada por Bronfenbrenner (1979/1996) enquanto forças ambientais que promovem o desenvolvimento das pessoas envolvidas na interação. Por essa perspectiva, presume-se que, no caso dessas crianças com necessidades especiais, as aquisições cognitivas, sociais, emocionais e seus processos de maturação biológica foram consolidados nas relações que estabeleceram em seus contextos ecológicos. Nesse sentido, não só as crianças, mas também seus pais, cuidadores, irmãos e outros familiares se desenvolveram, ao adquirir habilidades 
e conhecimentos para lidar com as necessidades especiais infantis.

Dentre as semelhanças observadas entre as três famílias, verificou-se que as atividades de alimentação/higiene, descanso e lazer são comuns a elas, as quais envolvem a participação dos pais, irmãs e babá, ocorrendo nos ambientes domésticos familiares.

Em relação àqueles grupos familiares nos quais as crianças adotadas estudam (GF1 e GF3) ocorre a transferência do tempo utilizado na escola, durante a semana, para a atividade de lazer, no final de semana, o que é acompanhado pelo aumento do tempo na companhia dos familiares. Ainda quanto às similaridades desses grupos familiares, seus membros se envolvem no direcionamento das crianças adotadas em terapias específicas cotidianamente.

No que se refere às diferenças entre os grupos familiares, percebeu-se que GF2 tem um padrão de atividade, tempo, companhia e ambiente que sofre pouca alteração dia após dia. No GF1, notou-se ser menor a quantidade de atividades e companhias. Por exemplo, foi apontada como inexistente a ação de assistir televisão, por exemplo, por motivo da cegueira profunda e surdez moderada da criança, que impedem seu envolvimento nessa atividade. Além disso, as pessoas predominantemente envolvidas nessas atividades são a criança adotada e sua babá. Já para GF3, as atividades, companhias, tempos utilizados e os ambientes são mais diversificados, por motivo do envolvimento de uma maior variedade de pessoas, provenientes de ambientes distintos, tais como da escola, da igreja, da casa dos avós, do ambiente do curso de capoeira, dentre outros. Isso permite argumentar que as rotinas familiares são configuradas e alteradas tanto a partir de características da pessoa, tais como a presença de deficiências ou doenças, quanto por aspectos do contexto ambiental, como, por exemplo, a renda familiar (Bronfenbrenner, 1979/1996).

Quanto às rotinas examinadas nos três grupos familiares, a partir do mapeamento das atividades realizadas, dos ambientes em que ocorreram, do tempo dedicado a elas e das pessoas nelas envolvidas, e com base em Churchill e Stoneman (2004), Fernandes et al. (2011) e SchultzKrohn (2004), supõe-se que as rotinas e seus elementos constituintes tenham contribuído para a consolidação de habilidades e conhecimentos valorizados socialmente, além de aquisições socioemocionais, linguísticas e escolares. Em resumo, o estudo das rotinas nos três grupos revelou tanto a dinâmica familiar, quanto os contextos ecológicos e culturais reguladores da vida das pessoas nelas envolvidas, conforme também destacaram Fiese et al. (2002) ao discorrerem sobre a importância deste tipo de pesquisa para compreender os contextos ecológicos nos quais a criança está se desenvolvendo.

\section{Referências}

Althoff, C. R., Renck, L. I., \& Sakae, S. V. S. S (2005). Famílias de crianças que necessitam de cuidados especiais: o impacto sobre a vida familiar. Família, Saúde e Desenvolvimento, 7(3), 221-229.
Bomar, P. J. (2004). Promoting health in families applying family research and theory to nursing practice. Philadelphia: Elsevier.

Brasil. (1990). Lei 8.069, de 13 de julho de 1990. Estatuto da Criança e do Adolescente. Retrieved from http//www.planalto. gov.br/ccivil_03/Leis/L8069.htm

Brasil. (2009). Lei 12.010, de 03 de agosto de 2009. Alterações no Estatuto da Criança e do Adolescente. Retrieved from http// www.planalto.gov.br/ccivil_03/Leis/L12010.htm

Bronfenbrenner, U. (1979/1996). A ecologia do desenvolvimento humano: Experimentos naturais e planejados. (M. A. V. Veronese, Trad.). Porto Alegre: Artes Médicas. (Trabalho original publicado em 1979)

Churchill, S. L., \& Stoneman, Z. (2004). Correlates of family routines in Head Start Families. Early Childhood Research, $6(1), 457-462$.

Deham, S. A. (2003). Relationships between Family Rituals, Family Routines, and Health. Journal of Family Nursing, 9(3), 305330, doi: 10.1177/1074840703255447.

Fernandes, G. C. M., Boehs, A. E., \& Rumor, P. C. F. (2011). Rotinas e rituais familiares: implicações para o cuidado. Ciência Cuidado Saúde, 10(4), 866-871, doi: 10.4025/cienccuidsaude. v10i4.18334.

Fiese, B., Tomcho, T., Douglas, M., Josephs, K., Poltrock, S., \& Baker, T. (2002). A review of 50 years of research on naturally occurring family routines and rituals: Cause for celebration? Journal of Family Psychology, 16, 381-390.

Freire, V. R. B. P. (2012). Famílias ribeirinhas amazônicas e o programa bolsa família. (Unpublished master's thesis). Universidade Federal do Pará, Belém.

Howe, G. W. (2002). Integrating Families Routines and Rituals With Other Family Research Paradigms: Comment on the Special Section. Journal of Family Psychology, 16, 437-440.

Schettini, S. S. M., Amazonas, M. C. L. A., \& Dias, C. M. S. B. (2006). Famílias adotivas: identidade e diferença. Psicologia em Estudo, Maringá, 11(2), 285-293.

Schultz-Krohn, W. (2004). The meaning of family routines in a homeless shelter. The American Journal of Occupational Therapy, 58(5), 531-542.

Sheely, A. (2010). Work characteristics and family routines in low-wage families. Journal of Sociology and Social Welfare, 27(3), 59-77.

Silva, S. D. B. (2007). Rotina, socialização e gênero. (Unpublished master's thesis). Universidade Federal do Pará, Belém.

Silva, S. S. C. (2006). Estrutura e dinâmica das relações familiares de uma comunidade ribeirinha da região amazônica. (Unpublished doctoral dissertation). Universidade de Brasília, Brasília.

Silva, D. G., Pontes, F. A. R., \& Silva, S. S. C (2011). Relações familiares de duas crianças ribeirinhas da Amazônia. Psicologia: Teoria e Prática, 13(3), 139-151.

Spagnola, M., \& Fiese, B. H. (2007). Family Routines and Rituals A Context for Development in the Lives of Young Children. Infants \& Young Children, 20(4), 284-299.

Yin, R. K. (2010). Estudo de caso: planejamento e métodos (A. Thorell, Trad.). Porto Alegre: Bookman. (Trabalho original publicado em 2003)

Recebido em 28.05.2013

Primeira decisão editorial em 11.07.2014

Versão final em 17.03.2015

Aceito em 17.03.2015 